\title{
Estudo comparativo das legislações de prevenção e combate a incêndio dos estados de Minas Gerais e Rio de Janeiro
}

A prevenção contra incêndios vem evoluindo devido aos acontecimentos desastroso ocorrido ao longo dos anos. A adoção de medidas preventivas é necessária para evitar os riscos de ocorrências de incêndios e diminuir os prejuízos gerados. No Brasil, a legislação e a fiscalização das medidas de proteção a combate a incêndio estão sob a responsabilidade do Corpo de Bombeiro, porém existe uma disparidade entre as legislações estadual devido suas autonomias e a grande variedade de atividades desenvolvidas na sociedade, o que dificulta a padronização das exigências técnicas. $O$ objetivo desse estudo foi a análise detalhada da atual situação das legislações estaduais de combate a incêndio e pânico de Minas Gerais e Rio de Janeiro, para que possa servir de apoio a futuras pesquisas relacionadas ao tema. Foram feitos levantamentos bibliográficos que abordavam o tema e estudo das legislações, visando analisar se o tema é abordado e as possíveis diferenças entre eles. Foi elaborado um quadro comparativo com os temas a serem discutidos. Verificou-se que a diferença na legislação entre os estados é preocupante, podendo encontrar uma diversidade de normas que estão em vigor nos estados brasileiros. Tais normas são dotadas de uma complexidade de parâmetros no dimensionamento de projetos de combate e prevenção de incêndios, tornando incerta a elaboração e posteriormente a execução. Sendo assim, 0 Brasil deverá assumir uma padronização com relação as legislações de forma a buscar soluções para prever e minimizar os riscos de incêndios, estando apto a fiscalizar e prevenir tais sinistros de forma eficiente.

Palavras-chave: Instrução Técnica; Pânico; Exigências Técnicas.

\section{Comparative study of the fire prevention and fighting laws of the states of Minas Gerais and Rio de Janeiro}

\begin{abstract}
Fire prevention has evolved due to the disastrous events that have occurred over the years. The adoption of preventive measures is necessary to avoid the risk of fire occurrences and to reduce the damage generated. In Brazil, the law and enforcement of fire protection measures are the responsibility of the Fire Brigade, but there are many differences between state laws due to their autonomy and the wide variety of activities developed in society, which makes it difficult to standardization of technical requirements. The purpose of this study was to give detailed analysis of the current situation of state fire and panic laws in Minas Gerais and Rio de Janeiro, so that it can support future research related to the theme. Bibliographic surveys were made to analyze if the theme is approached and the possible differences between them. A comparative table was prepared with the topics to be discussed. It was found that the difference in the legislation between the states is worrying, and may find a diversity of rules between in the Brazilian states. These rules have a complexity of parameters in firefighting and prevention projects, making their design and execution uncertain. Therefore, Brazil should standardize its laws in order to seek solutions to predict and minimize the risks of fire, being able to effectively monitor and prevent such problems.
\end{abstract}

Keywords: Technical instruction; Panic; Technical Requirements.

Topic: Engenharia Organizacional e do Trabalho

Reviewed anonymously in the process of blind peer.
Received: 12/04/2020

Approved: $29 / 07 / 2020$
Tamires Galvão Tavares Pereira (iD

Universidade Federal de Lavras, Brasil

http://lattes.cnpq.br/2193131970787592

http://orcid.org/0000-0003-3423-6962

tamires_florestal@hotmail.com

Douglas Lamounier Faria (iD

Universidade Federal de Lavras, Brasil

http://lattes.cnpq.br/2575514568061593

http://orcid.org/0000-0002-5405-8430

douglas.lamounier@yahoo.com

Jônatan Enan Carvalho de Araújo (i)

Centro Universitário de Lavras, Brasil

http://orcid.org/0000-0001-6576-0041

jaraujo.ambiental@gmail.com

\author{
Tony Matheus Carvalho Eugênio (iD) \\ Universidade Federal de Lavras, Brasi \\ http://lattes.cnpq.br/0823437440133853 \\ http://orcid.org/0000-0001-7049-2862 \\ tony.matheus@hotmail.com \\ Anirene Galvão Tavares Pereira \\ Escola Superior de Agricultura Luiz de Queiroz, Brasil \\ http://lattes.cnpq.br/1043222026498223 \\ http://orcid.org/0000-0003-1254-0963 \\ anirene eng.alimentos@hotmail.com \\ Lourival Marin Mendes (iD) \\ Universidade Federal de Lavras, Brasi \\ http://lattes.cnpq.br/1846557273818913 \\ http://orcid.org/0000-0002-1239-1040 \\ lourival@ufla.br
}

Referencing this:

PEREIRA, T. G. T.; FARIA, D. L.; ARAÚJO, J. E. C.; EUGÊNIO, T. M. C.; PEREIRA, A. G. T.; MENDES L. M.. Estudo comparativo das legislações de prevenção e combate a incêndio dos estados de Minas Gerais e Rio de Janeiro. Engineering Sciences, v.8, n.2, p.75-82, 2020. DOI: http://doi.org/10.6008/CBPC2318-3055.2020.002.0008 


\section{INTRODUÇÃO}

A descoberta e o domínio do fogo fizeram com que este se tornasse um facilitador na vida humana para cozinhar, iluminar e aquecer. $O$ fogo se propaga incidindo sobre qualquer forma de material combustível, podendo tornar-se incontrolável e, desse modo, dar origem aos incêndios, os quais podem ser provocados pelo ser humano (intencionalmente ou por negligência) ou por fontes naturais, principalmente os raios (SANT'ANNA et al., 2007).

Os fatores que contribuem para a propagação do fogo são: quantidades, volumes e espaçamentos dos materiais combustíveis no local; tamanho e situação das fontes de ignição; área e localização das janelas; velocidade e direção do vento; e também a forma e as dimensões do local. Todos esses fatores estão relacionados com a transmissão do calor e, se não houver medidas de prevenção eficazes, pode ocorrer de três formas: condução ou contato, convecção e radiação térmica (BRENTANO, 2015).

Prevenção e combate a incêndios é uma das principais medidas de controle de grandes acidentes e tragédias que deve ser abordada com muita seriedade, pois ela tem o objetivo de diminuir tais sinistros, preservando o patrimônio e a integridade física dos ocupantes (SCHMIDT, 2017). Segundo Andrade et al. (2015), o desenvolvimento da humanidade, desde os mais remotos tempos, foi e continua sendo submetido a constantes desafios, testando sua capacidade de sobrevivência. A prevenção contra incêndio em edificações evoluiu a partir de acontecimentos desastrosos causados por incêndios ao longo da história.

Nesse sentido, existem, no âmbito da segurança do trabalho, as Normas Regulamentadoras (NR's) do Ministério do Trabalho e Emprego. Segundo a NR no 23 (proteção contra incêndios), todos os empregadores devem adotar medidas de prevenção de incêndios, em conformidade com a legislação estadual e as normas técnicas aplicáveis, visando sempre à prevenção da saúde e à integridade física dos trabalhadores (BRASIL, 2011). Outras NR's, embora não específicas sobre o tema incêndios, também devem ter seu cumprimento observado pelas empresas visando a prevenção dos mesmos como, por exemplo, a NR no 10 Segurança em Instalações e Serviços Elétricos (2004), NR no 12 Segurança no Trabalho em Máquinas e Equipamentos (2011) e NR no 20 Segurança e Saúde no Trabalho com Inflamáveis e Combustíveis (2012).

Com o intuito de promover a prevenção de sinistros, uma série de medidas de combate ao fogo foram sendo adotadas, bem como o desenvolvimento de novos equipamentos, novas técnicas e o mais importante, novas legislações e constantes atualizações das mesmas (GOMES, 2014).

No Brasil, existem várias normas que regulamentam a prevenção e combate a incêndios. Merecem destaque as Instruções Técnicas (IT's) dos Corpos de Bombeiros Militares Estaduais, as quais estabelecem medidas de segurança contra incêndio e pânico nas edificações e áreas de risco, além de critérios e procedimentos para apresentação de processo de segurança contra incêndio e pânico junto aos respectivos órgãos dos Estados do Brasil (LUPATINI et al., 2014). É de competência de cada estado, por meio do corpo de bombeiro, legislar e fiscalizar a aplicação de medidas que minimizem o impacto decorrente de incêndios nas mais diversas atividades.

As atribuições dos corpos de bombeiros dificultam a padronização das exigências de segurança 
contra incêndios no Brasil, tendo em vista que cada unidade da federação tem a autonomia para estabelecer as próprias exigências por meio de suas instruções técnicas. Se por um lado, pode-se ter uma particularização das normas de acordo com as caraterísticas regionais de cada estado, por outro, tem-se como fragilidade a uniformidade dos requisitos técnicos a serem atendidos no Brasil (PEREIRA, 2017).

Segundo Araújo (2017), no Brasil pode-se observar uma crescente evolução das legislações de combate a incêndio e pânico, porém para cada estado encontram-se legislações distintas, sejam por prioridades características dos setores que impulsionam a economia local ou até mesmo pelo rigor com o que se encara os incêndios e os riscos que o mesmo pode oferecer. As leis e regulamentos de segurança contra incêndio e pânico foram construídos ao longo dos anos, incentivados, em sua maioria, por grandes incêndios, os quais mostraram que a evolução tecnológica e a verticalização das cidades aumentaram sobremaneira os riscos à vida dos usuários das edificações, exigindo do poder público e da sociedade técnica e científica o aprimoramento concomitante das medidas, sistemas construtivos e equipamentos que mitigassem tais riscos a níveis aceitáveis (RODRIGUES, 2016). Com o acontecimento da tragédia ocorrida na casa noturna (boate) Kiss (RS), em 2013, iniciaram-se novamente discussões a nível nacional sobre a necessidade de atualização das legislações estaduais e, principalmente, sobre a relevância em estabelecer requisitos únicos que garantam a eficiência e efetividade da segurança contra incêndios no Brasil (RODRIGUES, 2016).

Segundo Aquino (2015), a ocorrência de tragédias como a da Boate Kiss, apontam as deficiências na legislação contra incêndio aplicadas no Brasil, renovando a ideia de grandes mudanças na legislação no âmbito nacional. Isso porque pode-se encontrar uma diversidade de normas que estão em vigor nos estados brasileiros, dotadas de uma relevante complexidade de parâmetros no dimensionamento de projetos de combate e prevenção de incêndios, tornando incerta a elaboração e posteriormente a execução dos projetos do seguimento. Quando profissionais da área atuam em diferentes estados, se deparam com padrões distintos, causando, em muitos casos, interdições e até mesmo a negação do AVCB (Auto de Vistoria do Corpo de Bombeiros) de eventos temporários, por exemplo. Um dos grandes anseios da comunidade prevencionista do Brasil, seria a unificação da legislação brasileira contra incêndios. Segundo Seito (2008), o Brasil deveria contar com regulamentos a nível federal, pois são cerca de 5.564 municípios que em sua maioria não possuem um código de segurança contra incêndio.

Neste contexto, o objetivo desse estudo foi a análise detalhada da atual situação das legislações estaduais de combate a incêndio e pânico de Minas gerais e Rio de Janeiro. Com ênfase nos temas Fogos de Artifício, Espetáculos Pirotécnico, Pátio de Contêiner, Brigada de Incêndio.

\section{MATERIAIS E MÉTODOS}

Foram feitos os levantamentos das bibliografias que abordavam o tema em livros, artigos científicos e legislações governamentais. Após o agrupamento do material pesquisado, foram redigidos os textos, levando em consideração as principais publicações encontradas, com intuito de confrontar as ideias dos autores destacando os principais pontos relativos ao tema. 
Após a abordagem das publicações sobre o tema, iniciou-se o estudo das legislações estaduais, encontradas nos sites do corpo de bombeiros dos estados de Minas gerias e Rio de Janeiro, comparando os temas Fogos de Artifício, Espetáculos Pirotécnico, Pátio de Contêiner e Brigada de Incêndio, visando analisar se o tema é abordado, e as possíveis diferenças entre as legislações dos mesmos.

\section{RESULTADOS E DISCUSSÃO}

Após a análise das legislações sobre o tema Prevenção e Combate a Incêndios, foi observada a disparidade das mesmas de um estado para outro, seja por diferentes características individuais e/ou por questões organizacionais das entidades que detém a missão de regulamentar e/ou fiscalizarem o segmento. Os temos em discussão foram: Fogos de artifício, Espetáculos pirotécnico, Pátio de contêiner, Brigada de Incêndio, no qual estão classificados quanto ao estado e foram feitos comparativos.

Tabela 1: Comparativo da legislação dos Estados de Minas Gerais e Rio de janeiro.

\begin{tabular}{|l|l|l|}
\hline \multirow{2}{*}{ Tema } & \multicolumn{2}{|l|}{ Estados } \\
\cline { 2 - 3 } & MG & RJ \\
\hline Fogos de Artifício & $\mathrm{X}$ & $\mathrm{X}$ \\
\hline Espetáculos Pirotécnicos & $\mathrm{X}$ & \\
\hline Pátio de Contêiner & $\mathrm{X}$ & \\
\hline Brigada de Incêndio & $\mathrm{X}$ & $\mathrm{X}$ \\
\hline
\end{tabular}

\section{Análise Geral}

\section{Fogos de artifício e espetáculos pirotécnicos}

O tema 'fogo de artifício' é apresentado nos dois estados Minas Gerais e Rio de janeiro. Em Minas Gerais é encontrado na instrução técnica no 25 do Corpo de bombeiro Militar com o tema Fogos de artifício e pirotecnia, que tem como objetivo estabelecer as condições necessárias de segurança contra incêndio e pânico nas edificações destinadas ao comércio, fabricação e estocagem de fogos de artifício e espetáculos pirotécnicos. Cita de forma bem específica e clara sobre as aplicações, definições, procedimentos para indústria e depósitos, comércio varejista de fogos de artifício.

No Estado do Rio de Janeiro o tema fogos de artifício se encontra no decreto no 718, de 20 de maio de 1976, no qual dispõe sobre a fabricação, o trânsito, o deposito, o comercio e a queima de fogos de artifício. Dentro dos tópicos citados na instrução técnica no 25 encontra-se especificações, normas, procedimento a serem tomados no decorrer da sua implementação. Como por exemplo, em Procedimentos para indústria e depósito (IT no $25-5$ ), cita as normas específicas que deverão ser atendidas de acordo com o tema (NBR, $N R, I T$,

Apresenta ainda em outros tópicos dentro do mesmo tema, medidas de proteção para comércio varejista, e características que as edificações devem apresentar. Em estocagem são apresentadas medidas de acordo com cada classificação dos fogos estipulada pelo Regulamento para fiscalização de produtos controlados (R-105).

No Rio de janeiro o decreto é bastante restrito e nada específico. O tema Fogo de artifício é apresentado em apenas três páginas contendo 25 artigos, o que restringe e dificulta o trabalho para os 
profissionais da área em segurança contra incêndio. A maioria dos seus artigos aborda sobre multas que são aplicadas quando estão em desacordo com o decreto, ao invés de apresentar especificações, procedimento, normas entre outros requisitos como são apresentados na instrução técnica de Minas Gerais.

O Rio de janeiro por ser bem conhecido pelo seu espetáculo pirotécnico apresentado durante a virada no ano deveria apresenta uma legislação específica tanto para o tema Fogos de artifício como para pirotecnia. Com relação ao Espetáculo Pirotécnico como citado o estado do Rio de Janeiro não possui legislação específica para tema. Já Minas Gerais é apresentado juntamente com o tema Fogos de artifício. A Instrução técnica é de fácil entendimento e bem dinâmica, apresentando demonstrativos em imagens com as áreas reservadas para os fogos, local da apresentação e as distâncias para cada tipo de tubo de lançamento. Ainda traz em seu texto a obrigatoriedade em atender as exigências do Regulamento Técnico 03 sobre espetáculos pirotécnicos, do Exército Brasileiro. Fala também sobre as documentações e termo de responsabilidade que deve ser apresentado. Ainda nos anexos são apresentados os modelos de documentos a serem preenchidos e entregue às autoridades, e uma tabela com nomenclatura dos fogos de artifício com nome, descrição, efeito principal, facilitando o entendimento dos profissionais.

\section{Pátio contêiner}

Apenas o Estado de Minas Gerais apresenta legislação específica sobre o tema. Instrução Técnica no 31 do corpo de bombeiro apresenta sobre o tema e estabelece as medidas de segurança contra incêndio nas áreas dos pátios e terminais de contêineres, atendendo ao previsto no Regulamento de Segurança contra Incêndio e Pânico nas edificações e áreas de risco no Estado de Minas Gerais.

No estado do Rio de Janeiro não se encontra nenhuma legislação específica para o tema. É um tema pouco discutido, porém deve se ter uma atenção especial como para os demais temas relacionados à Segurança contra incêndio. É uma instrução técnica pequena que cita no seu texto, referencias de outras legislações, e procedimentos a serem seguido, porém de maneira bem superficial, ainda traz no tópico 5.2 sobre casos de pátios e terminais que utilizam o contêiner como módulo habitável, onde fala apenas que deve seguir as medidas de segurança contra incêndio prevista no Regulamento de Segurança contra Incêndio e Pânico nas edificações e áreas de risco no Estado de Minas Gerais.

Analisando o histórico de incêndios no Brasil, pode-se observar que nos últimos anos a região Sudeste do Brasil presenciou incidentes envolvendo contêiner como no caso do Ninho do Urubu no Estado do Rio de Janeiro em fevereiro de 2019 e Em São Paulo no ano de 2016 no pátio de contêiner no porto de santos.

A utilização de contêineres como forma de habitação deve levar em consideração diversos fatos, como por exemplo se são reutilizados ou novos, os produtos que eram transportados e ainda tipo de revestimento e a utilização de alguma tinta perigosa. A falta de ventilação também afeta o que deve ser armazenado posteriormente e quais as atividades que serão realizadas dentro ou ao redor dos contêineres. Alguns especialistas acham que eles têm o potencial de se tornar uma bomba pressurizada se contiverem o suficiente dos três elementos do triângulo do fogo: oxigênio, combustível e uma fonte de calor. Ainda apresenta que a reutilização de um contêiner de carga pode parecer uma solução pronta e de baixo custo 
para armazenamento, espaço de escritório ou mesmo moradia, mas é preciso se informar sobre os perigos e como minimizá-los. Como eles vêm ganhando espaço no setor da construção civil no Brasil deve atentar para a forma de como eles são produzidos, o que torna o processo de adaptação de um contêiner para um lugar habitável algo extremamente dispendioso.

Levando em consideração a crescente procura por contêineres para utilização como moradia entre outras finalidades, o Corpo de bombeiro dos Estados do Rio de Janeiro, Minas Gerais e todos os outros, devem rever suas legislações quanto ao tema Contêineres, acrescentando e incrementando mais especificações, tomando como bases outras legislações como as NBRs que abordam sobre o tema, preservando assim contra incêndios.

\section{Brigada de Incêndio}

Os dois estados apresentam legislações sobre o tema. O Estado de Minas Gerais na Instrução Técnica no 12 - Estabelece os critérios mínimos a serem exigidos pelo Serviço de Segurança Contra Incêndio e Pânico (SSCIP) referentes aos treinamentos, quantitativo e composição da brigada de incêndio para atuação em edificações, área de risco e eventos, quando for exigida essa medida de segurança contra incêndio e pânico. Rio de Janeiro o tema é apresentado na Resolução SEDEC 31 de 2013, que dispõe sobre o credenciamento de empresas especializadas para realizar curso de formação, curso de atualização de brigadistas voluntários de incêndio (BVI), sobre o serviço de brigadas de incêndio e do credenciamento de empresas especializadas para prestação de serviço de bombeiro civil $(\mathrm{BC})$ nas edificações, eventos e áreas de risco no estado do Rio de Janeiro e dá outras providências, e também de forma sucinta na Resolução SEDEC 279 de 2005 que dispõe sobre a avaliação e a habilitação do bombeiro profissional civil, o dimensionamento de brigadas de incêndio e estabelece exigências complementares para as edificações licenciadas ou construídas.

Ambos os Estados apresentam legislações bem completas, porém Minas Gerais sobre sai com relação ao Rio de Janeiro. Observa-se que a Instrução Técnica no 12 traz em seu texto temas que são importantes, mas que não são apresentados na Resolução do Rio de Janeiro como Programa de atividades da brigada de incêndio, Conteúdo programático para curso de formação de brigadistas e percentual de cálculo para a composição da brigada de incêndio. Alguns temas são apresentados nos dois estados, porém são tratados de forma diferente. Para instrutor de curso de formação de brigadistas na IT no 12 as exigências mínimas são Técnico de segurança do trabalho, Engenheiro de segurança do trabalho, profissional da área de saúde, militares das forças armadas e auxiliares (ativa ou reserva) que possuam no curso de formação/capacitação ou especialização disciplinas relacionadas à prevenção e combate a incêndio e na Resolução no 31 exige Engenheiro de Segurança do trabalho, Bombeiro civil mestre e Oficial bombeiro militar inativo, possuir curso de nível superior em entidade de ensino de formação de bombeiro militar, ou curso superior na área de engenharia ou arquitetura reconhecido no Brasil e não ter sido reformado por motivos disciplinares administrativos. Sendo assim um profissional da área com formação técnica em segurança do trabalho que atua em Minas Gerais, não pode exercer suas atividades de instrutor no estado do Rio de Janeiro, são nesses detalhes que a existência de uma legislação subsidiando e determinando padrões a serem seguidos surtiriam 
mais efeito.

Outra diferença são as nomenclaturas utilizadas pelos estados com relação à brigadista e suas funções. Pode-se observar que a junção dessas duas legislações se complementam. Cabe ressaltar que a padronização dessas legislações facilitaria o entendimento e o trabalho dos profissionais, já que não teria dificuldade em atuar em outros estados visto que a legislação seria a mesma, complementando apenas com algumas características regionais presentes nos estados.

\section{CONCLUSÕES}

Os acontecimentos de incêndio ao longo da história fizeram com que as autoridades repensassem nas medidas a serem tomadas e na reformulação das legislações, porém não sofreu alterações relevantes na prevenção de incêndios. Somos mais reativos e menos proativos, esperamos que os sinistros aconteçam para que possamos pensar em quais medidas precisam ser tomadas.

Em Minas Gerais se encontram instruções técnicas recentes e outras mais antigas. Esta disparidade provoca interpretações dispersas relacionadas ao tema, dificultando a execução de projetos e o trabalho dos profissionais da área de segurança contra incêndio. A unificação da legislação atingindo todas as esferas da administração pública tornaria a fiscalização mais eficaz.

No Rio de Janeiro foi observada a inexistência de um sistema mais didático, sendo necessária uma pesquisa mais aprofundada aos temas ao fazer os procedimentos comparativos com Estado de Minas Gerais. São encontrados na forma de aditamentos administrativos, decretos, leis, resoluções, Notas e Portarias, ou seja, o profissional encontra diversos obstáculos no decorrer do desenvolvimento seja elaboração de projetos, vistorias ou outros procedimentos.

A Região Sudeste conhecida pelo seu constante crescimento e desenvolvimento, ainda encontra divergência entre as legislações dos quatro estados. Minas Gerais é a segunda mais completa ficando atrás do Estado de São Paulo, que tem suas Instruções Técnicas bem completa e de referência para os demais. No Rio de Janeiro as legislações que abordam o tema proteção contra incêndio ainda são bem falhas, não existe um padrão a ser seguido como é encontrado em Minas Gerais e São Paulo.

\section{REFERÊNCIAS}

ANDRADE, C. C.; SOUZA, J. C.. Projeto de arquitetura: proteção contra incêndio em elementos estruturais de aço. Estação Científica, Macapá, v.5, n.2, p.49-68, 2015.

ARAÚJO, J. E. C.. Prevenção e Combate a Incêndios e Explosões no Sudeste do Brasil: Um Panorama das Legislações nos Quatro Estados. Monografia (Bacharelado em Engenharia de Segurança do Trabalho) - Centro Universitário de Lavras, Lavras, 2017.

AQUINO, L. M.. Aplicação das Normas de Segurança Contra Incêndio no Estado do Rio Grande do Norte: Uma Proposta de Atualização. Dissertação (Mestrado em Engenharia Civil) - Universidade Federal do Rio Grande do Norte, Natal, 2015.
BRASIL. Ministério do Trabalho e Emprego. NR 23: Proteção contra incêndios. Brasília: Ministério do Trabalho e Emprego, 2011.

BRENTANO, T.. A proteção contra incêndios no projeto de edificações. 3 ed. Porto Alegre: EDIPUCRS, 2015.

GOMES, T.. Projeto de Preservação e combate ao incêndio. Monografia (Bacharelado em Engenharia Civil) Universidade Federal de Santa Maria, Santa Maria, 2014.

LUPATINI, F. B.; CAMPOS, J. C. C.; MINETTE, L. J.; SCHETTINO, S.; CAMARINHA, A. C. M.. Análise das ocorrências de incêndios em indústrias do polo moveleiro de Ubá- Minas Gerais. 9 ed. Campos Gerais: Technoeng, 2014. 
RODRIGUES, E. E. C.. Sistema de Gestão da Segurança contra Incêndios e Pânico nas edificações: Fundamentação para uma Regulamentação Nacional. Tese (Doutorado em Engenharia Civil) - Universidade Federal do Rio Grande do Sul, Porto Alegre, 2016.

SANT'ANNA, C. M.; FIEDLER, N. C.; MINETTE, L. J.. Controle de incêndios florestais. Alegre: Os Autores, 2007.
SCHMIDT, J. S.. Plano de prevenção e combate a incêndios: estudo de caso em um centro de cultura em Porto LucenaRS. Monografia (Bacharelado em engenharia civil) Universidade Regional do Nordeste do Estado do Rio Grande do Sul, Santa Rosa, 2017.

SEITO, A. I.. A Segurança Contra Incêndio e Pânico no Brasil. São Paulo, 2008.

A CBPC - Companhia Brasileira de Produção Científica (CNPJ: 11.221.422/0001-03) detém os direitos materiais desta publicação. Os direitos referem-se à publicação do trabalho em qualquer parte do mundo, incluindo os direitos às renovações, expansões e disseminações da contribuição, bem como outros direitos subsidiários. Todos os trabalhos publicados eletronicamente poderão posteriormente ser publicados em coletâneas impressas sob coordenação da Sustenere Publishing, da Companhia Brasileira de Produção Científica e seus parceiros autorizados. Os (as) autores (as) preservam os direitos autorais, mas não têm permissão para a publicação da contribuição em outro meio, impresso ou digital, em português ou em tradução. 